\title{
Comparative Enactment of Fluorocarbon-free and Fluorocarbon-based Water Repellent Finishes on Cotton Single Jersey Fabrics
}

\author{
Kawser Parveen Chowdhury\#*, Sutapa Chowdhury^, Mohammad Alamin Hosain\#, Ahasan Al Mamun\#, Sk. \\ Nasimul Alahi" and Md. Saifur Rahman\#
}

\#Department of Wet Process Engineering, ^Department of Textile Fashion and Design, Bangladesh University of Textiles, 92 Shaheed Tajuddin Ahmed Avenue, Tejgaon, Dhaka-1208, Bangladesh

Received 12 Feb 2018, Accepted 15 April 2018, Available online 19 April 2018, Vol.8, No.2 (March/April 2018)

\begin{abstract}
In this study, single jersey derivatives of knit fabric were taken to evaluate the performance of water repellent finishes on knit fabrics properties. Here, polo pique and single jersey knit structured fabrics were treated with different types of water repellent chemicals at different formulations. The levels of water repellency of the fabrics were measured in accordance with ISO 4920:2012spray rating test method. To assess the performance of water repellent finishes on knit fabric properties, GSM, bursting strength test according to ASTM (D 3786-87) method, color fastness to wash according to ISO-105/ C06-C2S method, color fastness to water with ISO 105-E01 method and color fastness to rubbing with ISO-105-X 12 method were done. The results showed that the water repellent finish type and concentration were very important parameters to obtain water repellent fabrics with desirable properties.
\end{abstract}

Keywords: Water repellency, water repellent finish, polo pique, single jersey.

\section{Introduction}

Cotton is a natural fibre which have many superior quality along with comfort ability. Water repellency is one functional property that is required for cotton fabric without affecting the comfort ability. Water repellency is defined as the ability of a textile material to resist wetting and it is needed for protective clothing. The tendency of a water droplet to spread out over the fabric surface mainly depends on the contact angle of the water droplet and the fabric surface. Water repellent textiles have many uses including industrial, consumer and apparel purpose. This repellency can be achieved by implementing a thin surface layer of water repellent chemicals on textile fibres by the modification of surface energy of textiles with minimal effects on other functional properties like strength, flexibility, breathability, softness etc. (Bongiovanni R 2011 and Ferrero E 2012). Polymeric coating on cotton fabric must secure good homogeneity with preferred properties without deteriorating fabric's comfort ability like handle, breathability etc. When a water repellent chemicals applied on cotton fibre, a monomer that was present in water repellent chemical with the help of initiator mixture are absorbed onto the fibres and made the fabric water repellent by formation of the polymeric chains and graft bonds inside the textile

*Corresponding author's ORCID ID: 0000-0002-9218-2053 DOI: https://doi.org/10.14741/ijcet/v.8.2.34 structure. Furthermore, textile materials with modified surface can be obtained even by using low add-on of the monomer by the interpenetration of components and homogenous distribution of that monomers into the fibre. The modification process route, the use of non-toxic chemicals and solvents are some of the criteria of green chemistry. A fast, versatile, efficient process with the ecological orientation of industrial textile chemicals, is a good alternative of green chemistry. It has been reported that various types of fluorocarbons that are used for textile finishing, mainly used to impart water repellency along with oil repellency (Xu CH 2010, Castelvetro V2001, Shao H 2004, Lee H J 2007, Li Z R 2008, Roe B 2009).

These consist of perfluorinated carbon chains incorporating a polymer backbone with perfluoro groups as its side chains (Kasturiya N 2003). Some existing fluorochemicals are made with C8 carbon backbone chains that can release perfluorooctanesulfonate (PFOS) and perfluorooctanoic acid (PFOA) and other toxic and hazardousmaterials. Hence C6 based fluorocarbons were introduced, though their repellency performance and durability are less than C8 based ones and for these reason, some cross-linkers likealkyl urethane, were introduced (Mohsin M 2016). Fluorochemical finishings are usually available as water emulsions and are used to fabric by the pad-dry-cure method with a curing temperature around 160-1700C for a couple of minutes (Castelvetro V2001, Shao H 2004, Lee H J 
2007, Li Z R 2008).The water repellent properties were evaluated by measuring contact angle, wettability, moisture absorption and vapour permeability.

The first group of water repellent finishing agents is dispersion of fluorine compounds, namely fluorocarbon (FC).The final polymer, when applied to a fibre, should form a structure that presents a dense CF3 outer surface for maximum repellency. A typical structure is shown in below Figure 1. The length of the perfluorinated side chains should be about 8-10 carbons. Co-monomers are X, Y, for example are stearyl- or lauryl-meth-acrylate, butyl-acrylate, methylol- or epoxy-functional acrylates.

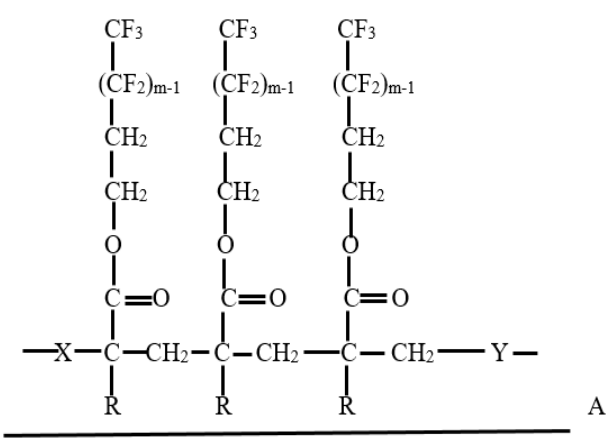

Figure 1. Fluorocarbon repellent on fibre surface. $\mathrm{M}=6-10 . \mathrm{X}$ and $\mathrm{Y}$ are co-monomers, mainly stearylates.

$\mathrm{R}=\mathrm{H}$ or $\mathrm{CH}_{3}$ (polyacrylic or polymethacrylic acid esters). A is the fibre surface (Schindler WD 2004).

The second group water repellent chemical is fluorocarbon resin with polymeric, hyperbranched dendrimers in a hydrocarbon.It is a novel development and is inspired by nature and therefore called bionic finishes. Fluorocarbon polymers are applied together with dendrimers, where the fluorocarbon chains are enriched on the surface and crystallize with the dendrimers. Dendrimers are highly branched oligomers with non-polar chains forming a star brush structure. They force the polar parts of the FC polymers to form the surface structure. The resulting polar and non-polar sandwich arrangements are highly ordered, causing better repellency effects, with lower amounts of fluorocarbon compared to dendrimer-free FC finishes.

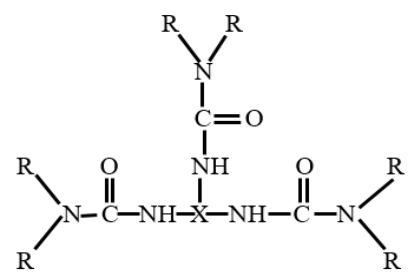

$$
\mathrm{R}=-\stackrel{\mathrm{O}}{\mathrm{C}}-\mathrm{C}_{17} \mathrm{H}_{35} \text { or } \quad-\left(\mathrm{CH}_{2}\right)_{\mathrm{n}} \stackrel{\stackrel{\mathrm{NHC}}{\mathrm{C}}-\mathrm{C}_{17} \mathrm{H}_{35}}{\|}
$$

Figure 2. A dendrimer structure synthesized from three distearyl-amines or amides and a trifunctional isocyanate $\mathrm{X}(\mathrm{N}=\mathrm{C}=0)$ (Schindler WD 2004)
Third group water repellent chemical is poly alkyl urethane resin. It is a renewably sourced nonfluorinated water repellent chemical. It contains $63 \%$ renewably sourced content derived from a variety of plant-based sources. It effectively repels water and water based liquid including fruit juice, hot coffee, red wine from cotton, synthetic blends fabrics.

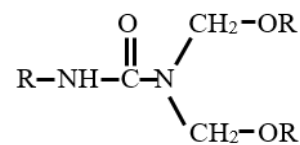

Figure 3. Alkyl urethane structure (Schindler WD 2004)

In the literature, a considerable number of studies on different water repellent chemicals, their application procedure, methods for improving the durability and their wash fastness and curing temperature have been reported (Sahin B 1996, Corpat J M 1997 Grottenmuller R 1998, Hangjin Q 2002).

There are almost insufficient work on the performance of water repellent finish and their effects on knit single jersey fabrics. The purpose of this study was to observe and evaluate the performance of what water repellent finish on which concentration affected single jersey knit fabrics properties after finishing.

\section{Materials and Methods}

\subsubsection{Fabrics}

$100 \%$ cotton single jersey fabrics (scoured, bleached) are used for this experiment to apply different types of water repellent chemicals by pad-dry-cure method The fabrics are supplied by Texeurop (BD) Ltd Bangladesh. Two types of single jersey knit structure derivatives are used here, such as polo pique and single jersey $(\mathrm{S} / \mathrm{J})$.

Table. 1. Types of fabrics with their specification

\begin{tabular}{|c|c|c|c|}
\hline $\begin{array}{c}\text { Name of Knit } \\
\text { Fabrics }\end{array}$ & GSM & Count & Composition \\
\hline Polo pique & 200 & $28 \mathrm{Ne}$ & $100 \%$ cotton \\
\hline S/J & 160 & $28 \mathrm{Ne}$ & $100 \%$ cotton \\
\hline
\end{tabular}

These fabrics presents a $0^{0}$ contact angle with water, as the drops were absorbed immediately showing excellent hydrophilic character of cotton. Supplied fabrics are first dyed by using following recipe which is stated in Table 2 in Microfibre lab. 
Table 2. Dye application bath of single jersey fabrics are listed

\begin{tabular}{|c|c|c|c|c|c|}
\hline Dyes and chemicals & $\begin{array}{l}\text { Polo Pique fabric } \\
\text { (Turquise color) }\end{array}$ & Recipe & \multicolumn{2}{|c|}{$\begin{array}{l}\text { Single jersey fabric } \\
\text { (Orange color) }\end{array}$} & Recipe \\
\hline Dyestuff & $\begin{array}{c}\text { Reacto bond Turquise } \\
\text { Blue G } 133 \%\end{array}$ & $4 \%$ & \multicolumn{2}{|c|}{ Reacto bond Orange $2 \mathrm{RX}$} & $0.5 \%$ \\
\hline Auxiliaries & \multicolumn{5}{|c|}{$\begin{array}{ll}\text { Jinlev ECO CL 225 (Levelling agent) } & : 25 \mathrm{~g} / \mathrm{l} \\
\text { Jintexy Ec SQ 117CA (Sequestering agent) } & : 25 \mathrm{~g} / \mathrm{l} \\
\text { Jingen Lub CBA (Wetting agent) } & : 50 \mathrm{~g} / \mathrm{l}\end{array}$} \\
\hline \multirow{6}{*}{ Basic Chemicals } & & & Polo pique & & $\mathrm{S} / \mathrm{J}$ \\
\hline & Glauber's sa & & $60 \mathrm{~g} / \mathrm{L}$ & & $16 \mathrm{~g} / \mathrm{L}$ \\
\hline & Soda ash & & $20 \mathrm{~g} / \mathrm{L}$ & & $9 \mathrm{~g} / \mathrm{L}$ \\
\hline & Temperatu & & $80^{\circ} \mathrm{C}$ & & $60^{\circ} \mathrm{C}$ \\
\hline & \multicolumn{4}{|c|}{$90 \mathrm{~min}$} & \\
\hline & \multicolumn{2}{|c|}{$\mathrm{M}: \mathrm{L}$} & \multicolumn{2}{|c|}{ 1:10 } & \\
\hline After treatment & \multicolumn{5}{|c|}{$\begin{array}{c}\text { Cold wash } \\
\text { Acid wash } 2 \mathrm{cc} / \mathrm{L} \text { for } 4-5 \mathrm{~min} \text { (Green acid) } \\
\text { Hot wash at } 95^{\circ} \mathrm{C} \text { for } 7 \mathrm{~min} \\
\text { Soap wash } 2 \mathrm{~g} / \mathrm{L} \text { for } 7 \mathrm{~min}(\text { Soaping agent Jingen SP AW5045) } \\
\text { Hot wash at } 95^{\circ} \mathrm{C} \text { for } 7 \text { min }(2 \text { times) and then dry. }\end{array}$} \\
\hline
\end{tabular}

After dyeing the fabrics are then finished with three different water repellent chemicals in three different concentrations to investigate the effect of water repellent chemicals and concentrations on water repellency, other physical and color fastness properties of the fabrics.

\subsubsection{Water repellent chemicals}

First is fluorocarbon (FC) (trade name Nuva TTC which is a fluorocarbon based water repellent agent, weakly cationic, dispersion of fluorine compound, Clariant), second is $\mathrm{FC}+$ dendrimers(FC+D) (trade name Rucostar EEE6 which is fluorocarbon (C6) resin with polymeric, hyperbranched dendrimers in a hydrocarbon, cationic, Rudolf chemie)) and third is poly alkyl urethane (alkyl urethane) (Zelan R3 which is a alkyl urethane water repellent chemicals, cationic, Huntsman) water repellent chemicals are used in this experiment.

\subsubsection{Water repellent application bath}

Single jersey fabrics are treated with three different water repellent chemicals at three different concentrations $(70 \mathrm{~g} / \mathrm{L}, 90 \mathrm{~g} / \mathrm{L}$ and $100 \mathrm{~g} / \mathrm{L})$ from a separate bath with the similar bath condition. First is fluorocarbon (FC), second is fluorocarbon with dendrimers $(\mathrm{FC}+\mathrm{D})$ and third is alkyl urethane (alkyl urethane) water repellent chemical solutions are prepared. The process parameters are adopted as recommended by the supplier. The name of chemicals, bath set up are given in Table 3. Horizontal Pad-Mangle machine (Rapid, Xiamen Rapid Co Ltd, China) is used for padding with $4.5 \mathrm{rpm}$ fabric speed and $2.3 \mathrm{~kg} / \mathrm{cm}^{2}$ padding pressure. Channel precision oven machine (china) is used for drying and Labtec Steamer machine (Newave Lab equipments Co Ltd, Taiwan) is used for curing.
Table 3. Water repellent application bath

\begin{tabular}{|c|c|c|c|c|}
\hline \multicolumn{2}{|c|}{ Finishing bath set up } & $\mathrm{FC}$ & $\mathrm{FC}+\mathrm{D}$ & $\begin{array}{l}\text { Alkyl } \\
\text { urethane }\end{array}$ \\
\hline \multirow{4}{*}{$\begin{array}{c}\text { Name } \\
\text { of } \\
\text { chemicals }\end{array}$} & Resin & $\begin{array}{c}70,90, \\
100 \mathrm{~g} / \mathrm{L} \\
\end{array}$ & $\begin{array}{c}70,90, \\
100 \mathrm{~g} / \mathrm{L} \\
\end{array}$ & \begin{tabular}{|c|}
70,90, \\
$100 \mathrm{~g} / \mathrm{L}$ \\
\end{tabular} \\
\hline & Acetic acid & $\begin{array}{l}01 \mathrm{ml} / \mathrm{L} \\
\text { as } \\
\text { required } \\
\text { for } \\
\mathrm{p}^{\mathrm{H}} 4-5\end{array}$ & $\begin{array}{l}01 \mathrm{ml} / \mathrm{L} \text { as } \\
\text { required } \\
\text { for } \mathrm{p}^{\mathrm{H}} 4-5\end{array}$ & $\begin{array}{l}01 \mathrm{ml} / \mathrm{L} \\
\text { required } \\
\text { for } \mathrm{p}^{\mathrm{H}} 4-5\end{array}$ \\
\hline & $\begin{array}{l}\text { Phobol XAN } \\
\text { g/L (booster) }\end{array}$ & -- & -- & $10 \mathrm{~g} / \mathrm{L}$ \\
\hline & $\begin{array}{l}\text { Invadine } \\
\text { PBN(wetting } \\
\text { agent) }\end{array}$ & -- & -- & $5 \mathrm{~g} / \mathrm{L}$ \\
\hline \multirow{4}{*}{$\begin{array}{l}\text { Application } \\
\text { Parameters }\end{array}$} & Padding & \multicolumn{3}{|c|}{$80 \%$ pick up } \\
\hline & Drying & \multicolumn{3}{|c|}{$120^{\circ} \mathrm{C}$ for $3 \mathrm{~min}$} \\
\hline & Curing & \multicolumn{3}{|c|}{$160^{\circ} \mathrm{C}$ for $2 \mathrm{~min}$} \\
\hline & $\begin{array}{c}\text { Padder } \\
\text { Pressure }\end{array}$ & \multicolumn{3}{|c|}{1 bar } \\
\hline
\end{tabular}

Phobol XAN: It is mainly used as booster or extender for water and oil repellent products and its chemical constitution is dispersion of oxime blocked isocyanate. Cationic, light beige color, $\mathrm{PH}^{\mathrm{H}}$ about 2.5-4.5, and dissolve in cold water to add to the finishing bath.

Invadine PBN: Wetting agent for oil and water repellent finishes. The chemical constitution is surface active preparation of ethyoxylated fatty alcohol and aliphatic ether alcohol. Anionic, clear to opalescent liquid, $\mathrm{p}^{\mathrm{H}}$ about 7.5-9.5, dissolve in cold water.

\subsection{Methods}

\subsubsection{Water repellent evaluation test}

There are two types of water repellent evaluation test are used.

a) Drop test (it checks the contact angle)

b) Spray rating test (The spray rating tests are 
evaluted by using ISO 4920:2012 test method where 5 grade of surface resistance rating expresses that there will be no sticking or wetting of the upper fabric surface, 4 grade rating expresses that there will be only slight random wetting on the upper fabric surface, 3 grade means there will be wetting at the spray points on the upper surface of fabric while a fabric with complete wetting was assigned a 0 rating. Spray rating tests were done by Spray Rating Tester by James $\mathrm{H}$. Heal \& Co. Ltd. Halifax, England)

\subsubsection{Physical and chemical testing}

Each samples are tested in the standard atmosphere, $25 \pm 2^{\circ} \mathrm{C}$ temperature and $65 \% \mathrm{RH}$ after conditioning 24 hrs.

2.2.2.1. GSM test: GSM test is done by GSM cutter from James H. Heal \& Co. Ltd. Halifax, England according to ASTM (D 3776-79) method.

2.2.2.2. Bursting strength test: It is done by bursting strength tester from SDL Atlas according to ASTM D 3786-87 method.

2.2.2.3. Color fastness to wash: Color fastness to wash is measured with ISO- $105 \mathrm{C} 2 \mathrm{~S}$ method.

2.2.2.4 .Color fastness to water: It is done by ISO 105E01 method.

2.2.2.5 Color fastness to rubbing: The resistance of color against rubbing of dyed fabrics (dry and wet) are evaluated with ISO-105-X 12 method.

\section{Result and Discussion}

\subsection{Water repellent evaluation test}

\subsubsection{Drop test}

Three different types of water repellent chemicals are used among them two chemicals are fluorocarbon based and one is alkyl urethane based. Water repellent solutions (trade name Nuva TTC, Rcostar EEE6, \& Zelan R3) are prepared in $70 \mathrm{~g} / \mathrm{L}, 90 \mathrm{~g} / \mathrm{L}$ and $100 \mathrm{~g} / \mathrm{L}$ concentrations and applied on different $100 \%$ cotton knit single jersey dyed fabrics. Two types of single jersey knit fabrics are used in here which are single jersey $(\mathrm{S} / \mathrm{J})$ and polo pique. This is the visual test to evaluate the water repellency. If the material surface has lower surface tension than water, then that material is called water repellent which means if a water drop is placed on water repellent material then the drop will rest up on it without penetration. Here are the visual appearances of untreated and treated fabrics are shown in Figure 4, showing that treated fabrics are water repellent.

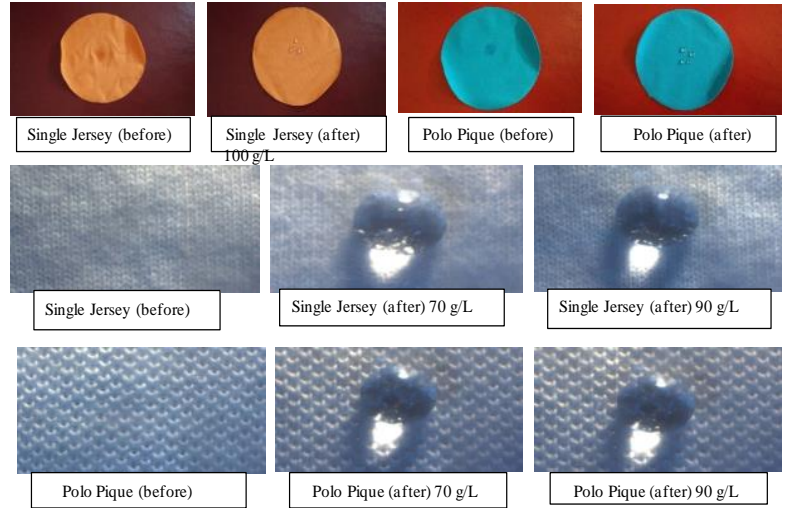

Figure 4. Some physical appearances of untreated and treated fabrics with alkyl urethane; color fabricsare treated with $100 \mathrm{~g} / \mathrm{L}$ conc. and white fabrics are untreated and treated with $70 \mathrm{~g} / \mathrm{L}$ and $90 \mathrm{~g} / \mathrm{L}$ conc. of alkyl urethane.

\subsubsection{Spray rating test}

Three water repellent chemical's solutions are prepared in different concentrations such as $70 \mathrm{~g} / \mathrm{L}, 90$ $\mathrm{g} / \mathrm{L}$ and $100 \mathrm{~g} / \mathrm{L}$ conc. and applied on knit single jersey dyed fabrics ( $\mathrm{S} / \mathrm{J}$ and polo pique). These treated fabrics are evaluated using ISO 4920:2012 method. The evaluated rating of the samples are given in chart. Schindler and Hauser described that by completing the pad-dry-cure process, the heat treatment changes perfluoro side chains to almost crystalline structures to achieve optimal water repellency (Schindler WD 2004). Compared with the untreated fabric, the finished fabrics had good water repellency with around 3-5 grades.

Table 4: Spray rating of different fabrics treated with water repellent chemicals at $70 \mathrm{~g} / \mathrm{L}, 90 \mathrm{~g} / \mathrm{L}$ and 100 $\mathrm{g} / \mathrm{L}$ conc

\begin{tabular}{|c|c|c|c|c|}
\hline $\begin{array}{c}\text { Conc. } \\
(\mathrm{g} / \mathrm{L})\end{array}$ & Fabric & FC & Alkyl urethane & FC+D \\
\hline \multirow{2}{*}{70} & Polo pique & $3-4$ & $3-4$ & 4 \\
\cline { 2 - 5 } & S/J & $3-4$ & $3-4$ & 4 \\
\hline \multirow{2}{*}{90} & Polo pique & 4 & $4-5$ & $4-5$ \\
\cline { 2 - 5 } & S/J & 4 & 4 & 4 \\
\hline \multirow{2}{*}{100} & Polo pique & $4-5$ & $4-5$ & $4-5$ \\
\cline { 2 - 5 } & S/J & 4 & 4 & 4 \\
\hline
\end{tabular}

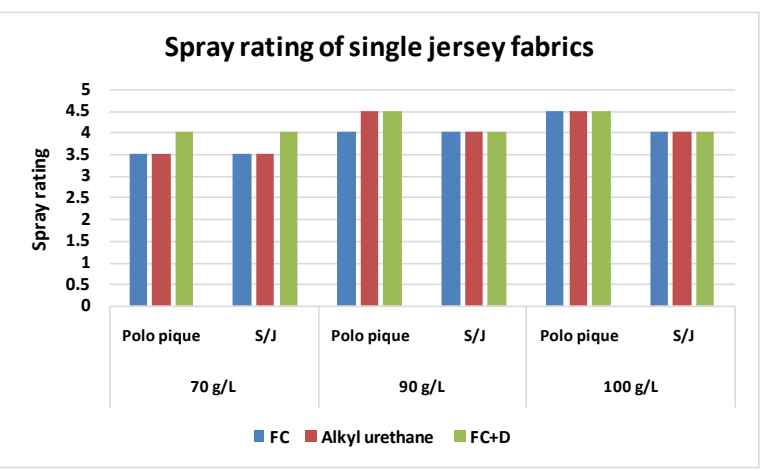

Figure 5. Spray rating of different single jersey fabrics treated with water repellent chemicals at $70 \mathrm{~g} / \mathrm{L}$, 90g/L and $100 \mathrm{~g} / \mathrm{L}$ conc. 
From the above Figure 5 and Table 4, it is clearly evident that indifferent concentrations, water repellency rating varies with different single jersey fabrics. In $70 \mathrm{~g} / \mathrm{L}$ conc., comparatively good spray rating is found by using $\mathrm{FC}+\mathrm{D}$ water repellent chemical for both S/J and polo pique fabrics. In $90 \mathrm{~g} / \mathrm{L}$ conc., water repellency rating has found better for both alkyl urethane and FC+D water repellent chemicals for both $\mathrm{S} / \mathrm{J}$ and polo pique fabrics. Among the fabrics, polo pique fabric shows the best rating without any changing for $\mathrm{FC}+\mathrm{D}$ water repellent chemical by that conc. Particularly for $100 \mathrm{~g} / \mathrm{L}$ conc., fluorocarbon gives the best result for both fabrics rather than others and in high concentration all the chemicals show better result for both fabrics.

\section{2. Analysis of GSM}

The GSM tests are done for all fabrics treated three different water repellent agents with three different concentration and found results are given in below chart:

Table 5. GSM of different fabrics treated with water repellent chemicals at $70 \mathrm{~g} / \mathrm{L}, 90 \mathrm{~g} / \mathrm{L}$ and $100 \mathrm{~g} / \mathrm{L}$ conc.

\begin{tabular}{|c|c|c|c|c|c|}
\hline $\begin{array}{c}\text { Fabric } \\
\text { Name }\end{array}$ & $\begin{array}{c}\text { GSM } \\
\text { (Before } \\
\text { ) }\end{array}$ & $\begin{array}{c}\text { Conc. } \\
\text { (g/L) }\end{array}$ & FC & $\begin{array}{c}\text { Alkyl } \\
\text { urethane }\end{array}$ & FC+D \\
\hline $\begin{array}{c}\text { Polo } \\
\text { pique }\end{array}$ & 200 & \multirow{2}{*}{70} & 210 & 213 & 211 \\
\hline S/J & 160 & & 172 & 173 & 172 \\
\hline $\begin{array}{c}\text { Polo } \\
\text { pique }\end{array}$ & 200 & \multirow{2}{*}{90} & 215 & 215 & 214 \\
\hline S/J & 160 & & 175 & 175 & 174 \\
\hline $\begin{array}{c}\text { Polo } \\
\text { pique }\end{array}$ & 200 & \multirow{2}{*}{100} & 218 & 217 & 216 \\
\hline S/J & 160 & & 178 & 180 & 179 \\
\hline
\end{tabular}

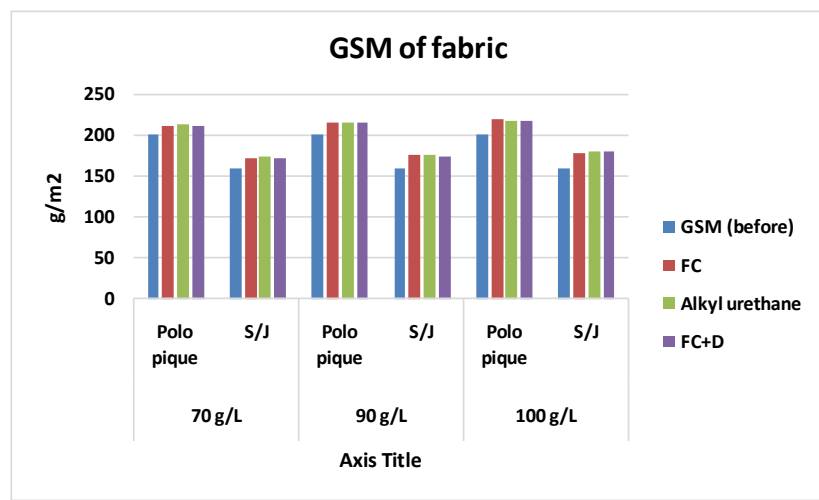

Figure 6. GSM of different fabrics treated with water repellent chemicals at conc. of $70 \mathrm{~g} / \mathrm{L}, 90 \mathrm{~g} / \mathrm{L}$ and 100

$$
\mathrm{g} / \mathrm{L} \text {. }
$$

After chemical implementation of the different single jersey fabrics with various conc. from Figure 6 and Table 5, GSM has increased because chemical has covered up all the pores of the fabric and a chemical coating is created on the fabric. Therefore, the water is not allowed to penetrate into the fabric.

\subsection{Bursting Strength test}

Burstingstrength plays a vital role after water repllent finish.It was done according to ASTM (D 3786-87) method to evaluate the treated knit fabric's bursting strength.In here,in the chart the bursting strength of the cotton single jersey knit fabric shows slight detoriation occurs and it is obviously taken into account as resin crosslinks in amorphousregion of cellulose leading lower flexibility and harsh handfeel. Though it is marginal for the fabric to go for the next proceedings.

Table 6. Bursting strength of single jersey fabrics treated with water repellent chemicals at $70 \mathrm{~g} / \mathrm{L}, 90$ $\mathrm{g} / \mathrm{L}$ and $100 \mathrm{~g} / \mathrm{L}$ conc.

\begin{tabular}{|c|c|c|c|c|c|}
\hline Fabric & \multirow{2}{*}{$\begin{array}{c}\text { Bursting } \\
\text { Strengh } \\
\text { Name }\end{array}$} & $\begin{array}{c}\text { Conc. } \\
\text { (kpefore) }\end{array}$ & FC & $\begin{array}{c}\text { Alkyl } \\
\text { urethane }\end{array}$ & FC+D \\
\hline $\begin{array}{c}\text { Polo } \\
\text { pique }\end{array}$ & 328.3 & \multirow{2}{*}{70} & 294.2 & 293.7 & 300.5 \\
\hline S/J & 304.7 & & 278.0 & 280.6 & 277.6 \\
\hline $\begin{array}{c}\text { Polo } \\
\text { pique }\end{array}$ & 328.3 & \multirow{2}{*}{90} & 281.1 & 290.5 & 286.9 \\
\hline S/J & 304.7 & & 269.9 & 271.7 & 278.2 \\
\hline $\begin{array}{c}\text { Polo } \\
\text { pique }\end{array}$ & 328.3 & \multirow{2}{*}{100} & 280.3 & 285.3 & 285.4 \\
\hline S/J & 304.7 & & 256.0 & 266.3 & 255.9 \\
\hline
\end{tabular}

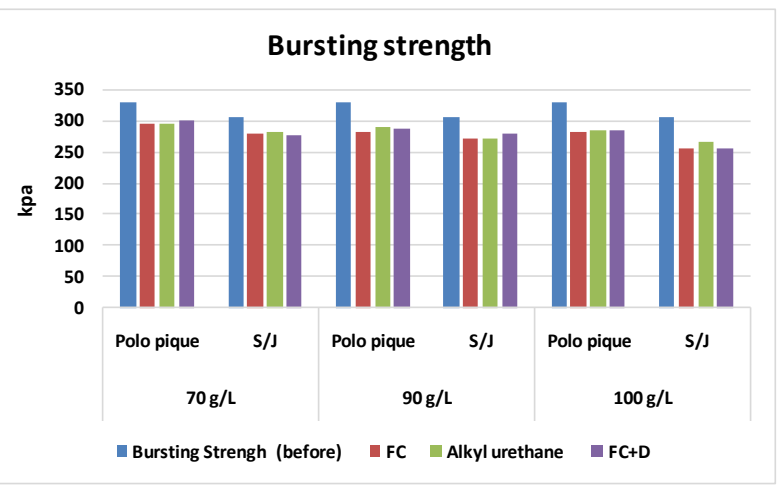

Figure 7. Bursting Strength (kpa) of different fabrics treated with water repellent chemicals at conc. $70 \mathrm{~g} / \mathrm{L}$, $90 \mathrm{~g} / \mathrm{L}$ and $100 \mathrm{~g} / \mathrm{L}$.

From the above chart in Figure 7 and Table 6, it is clear that after water repellent finish the fabric strength is decreased and it's reasonable. The fabric strength is decreased by increasing of concentration. The bursting strength of knit fabric reduced because of effect of the cellulosic fiber during cross linking process. When the water repellent chemicals form cross link with the cotton free $\mathrm{O}-\mathrm{H}$ group in the amorphous region, it makes stiff of the fabric and moreover, cross linking reaction is done mainly in acidic condition which are also responsible for the loss of the fabric bursting strength. 


\subsection{Color fastness to wash}

The wash fastness of water repellent treated fabric with different concentration were measured with ISO105/ C06-C2S method and rated under grey scale for two types of measurement, one was for color change and another was for color staining. The rated chart was given below in Table 7.At first the sample was washed with standard recipe and then color change was measured to the washed sample with the standard sample and compared. Color staining was also measured with grey scale with the help of multifibre fabric. The ratings were given below for 70, 90 and 100 $\mathrm{g} / \mathrm{L}$ conc. for different water repellent chemicals. It showed the best color fastness to wash with alkyl urethane and $\mathrm{FC}+\mathrm{D}$ water repellent chemicals than FC chemical for fabrics at different conc. The improvement of wash fastness of water repellent finished fabric was because of the dye molecules trapped inside the crosslinking film.

Table 7. Color fastness to wash of single jersey fabrics treated with water repellent chemicals at $70 \mathrm{~g} / \mathrm{L}$, $90 \mathrm{~g} / \mathrm{L}$ and $100 \mathrm{~g} / \mathrm{L}$ conc.

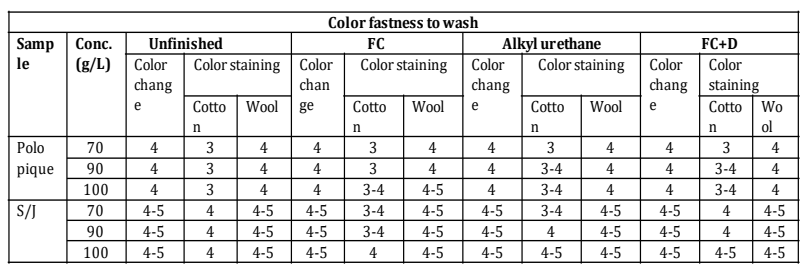

\subsection{Color fastness to water}

Color fastnessto waterof different water repellent treated fabrics were rated under grey scale for two types of measurement, one is for color change and another is for color staining. Color fastness to water is measured with ISO 105 E01 method. Color staining was measured with grey scale with the help of multifibre fabric. The rated chart was given below in Table 8. The water fastness of all water repellent treated fabrics were measured at 70, 90, and $100 \mathrm{~g} / \mathrm{L}$ conc. The water fastness of alkyl urethane and $\mathrm{FC}+\mathrm{D}$ water repellent chemicals showed better result than FC chemicals for single jersey fabrics at different conc. Moreover, the water fastness was improved with the increase of water repellent chemicals conc.

Table 8. Color fastness to water of single jersey fabrics treated with water repellent chemicals at $70 \mathrm{~g} / \mathrm{L}$, 90g/L and $100 \mathrm{~g} / \mathrm{L}$ conc.

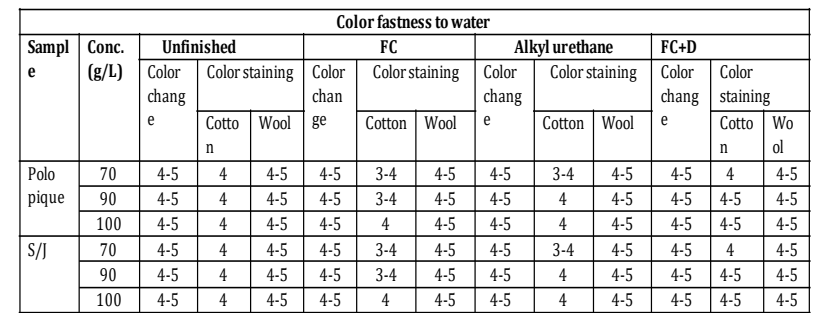

\subsection{Rubbing fastness}

The resistance of color against rubbing of dyed fabrics (dry and wet) were evaluated with ISO-105-X 12 method. The rubbing fastness of water repellent treated fabric with different concentration was rated under grey scale for the measurement of color staining against dry and wet white fabric. The rated chart of rubbing fastness for wet and dry rub was given below in Table. 9. It showed that both dry and wet rub are increased after water repellent finish on conc. $90 \mathrm{~g} / \mathrm{L}$ and $100 \mathrm{~g} / \mathrm{L}$ as more resin make more coating on fabric surface thus preventing color staining against rub.

Table 9.Rubbing fastness of single jersey fabrics treated with water repellent chemicals at $70 \mathrm{~g} / \mathrm{L}$, 90g/L and 100g/L conc.

\begin{tabular}{|c|c|c|c|c|c|c|c|c|c|}
\hline \multicolumn{10}{|c|}{ Color Fastness to rubbing } \\
\hline \multirow{2}{*}{ Fabric } & \multirow{2}{*}{$\begin{array}{l}\text { Conc. } \\
(\mathrm{g} / \mathrm{L}) \\
\end{array}$} & \multicolumn{2}{|c|}{\begin{tabular}{|l|} 
Untreated \\
\end{tabular}} & \multicolumn{2}{|c|}{ FC } & \multicolumn{2}{|c|}{ Alkyl urethane } & \multicolumn{2}{|c|}{$\mathrm{FC}+\mathrm{D}$} \\
\hline & & Dry & Wet & Dry & Wet & Dry & Wet & Dry & Wet \\
\hline \multirow[t]{3}{*}{ Polopique } & 70 & 4 & 3 & 4 & 3 & 4 & 3 & 4 & 3 \\
\hline & 90 & 4 & 3 & 4 & 3 & 4 & $3-4$ & 4 & $3-4$ \\
\hline & 100 & 4 & 3 & 4 & 3-4 & 4 & $3-4$ & 4 & $3-4$ \\
\hline \multirow[t]{3}{*}{ S/J } & 70 & 4 & 3 & 4-5 & $3-4$ & $4-5$ & $3-4$ & $4-5$ & 4 \\
\hline & 90 & 4 & 3 & $4-5$ & 4 & $4-5$ & 4 & $4-5$ & 4 \\
\hline & 100 & 4 & 3 & 4-5 & 4 & $4-5$ & 4-5 & $4-5$ & $4-5$ \\
\hline
\end{tabular}

From the data sheet (staining), it is found that all three $\mathrm{FC}, \mathrm{FC}+\mathrm{D}$ and alkyl urethane water repellent finishes showed good rubbing (dry and wet) fastness than untreated ones for single jersey fabrics as rubbing fastness is mainly depends on dye structure and chemical's add on. The rubbing fastness improves with the chemical conc. increases as repellent chemical make a thin coating on fabric surface.Alkyl urethane and $\mathrm{FC}+\mathrm{D}$ show better rubbing fastness in all single jersey knit fabrics than FC.

\section{Conclusion}

In this study, the effect of water repellent finishes were investigated on single jersey derivatives of knit fabrics (polo pique and S/J) with different conc. To do so, 24 repellent treated different structured knit fabrics samples were tested and obtained results were evaluated. Different physical and chemical test results showed that the repellent types and their conc. ranges significantly influenced water repellency of single jersey fabrics. When fluorocarbon with dendrimers $(\mathrm{FC}+\mathrm{D})$ was used, then the best water repellency is obtained. Changing concentration from lower to higher conc., gives gradually increased water repellency, regardless of repellent chemical type. However, unlike the findings of previous research works which described that if the water repellent was used with higher concentration, strength is decreased. The repellent chemicals and their changing conc. did not cause significant change to bursting strength of knit fabrics. There was no remarkable deviation is observed in GSM on the basis of water repellent chemicals and their varying concentrations. A higher in repellent conc. caused a higher wash fastness, water fastness and rubbing fastness. Finishing after dyeing had no effect 
on water repellency is another important conclusion of this work.

\section{Acknowledgement}

We would also like to express our deep gratitude to ARCHROMA and MICRO FIBRE for providing us the lab facilities, essentially used during the work. We would also like to thank TEXEUROP for providing us sample fabrics. Again special gratitude also goes to the Wet Processing Lab \& the TTQC Lab of Bangladesh University of Textiles (Butex).

\section{References}

Bongiovanni R, Zeno E, Pollicino A, Serafini PM, Tonelli C, (2011), UV-light induced grafting of fluorinated monomer onto cellulose sheets, Cellulose, 18, 117-126.

Ferrero E, Periolatto M, Udrescu C, (2012), Water and oilrepellent coatings of perfluoro-polyacrylate resins on cotton fibres: UV curing in comparison with thermal polymerization, Fibre. Polym, 13, 191-198.

Xu CH, Jia ST, Zhang J, Ma JZ, (2010), Large-area fabrication of superhydrophobic surfaces for practical applications: An overview, Sci. Technol. Adv. Mat., 11, 1-15.

Castelvetro V, Francini G, Ciardelli G, Ceccato M,(2001), Evaluating fluorinated acrylic lattices as textile water and oil repellent finishes, Text. Res. J, 71, 399-406.

Shao H, Sun J Y, Meng W D, Qing F L, (2004), Water and oil repellent and durable press finishes for cotton based on a perfluoroalkyl-containing multi-epoxy compound and citric acid, Text. Res. J, 74, 851-855.
Lee H J, Michielsen S, (2007), Preparation of a superhydrophobic rough surface, J. Polym. Sci. Part B, Polym. Phys, 45, 253-261.

Li Z R, Fu K J, Wang L J, Liu F, (2008),Synthesis of a novel perfluorinated acrylate copolymer containing hydroxyethyl sulfone as crosslinking group and its application on cotton fabrics, J. Mater. Process. Technol, 205, 243-248.

Roe B, Zhang X, (2009), Durable hydrophobic textile fabric finishing using silica nanoparticles and mixed silanes, Text. Res. J, 79, 1115-1122.

Kasturiya N, Bhargava GS, (2003), Liquid repellency and durability assessment: A quick technique, J. Ind. Text., 32, 187-222

Mohsin M, Sarwar N, Ahmed S, Rasheed A, Ahmad F, Afzal A Zafar S,(2016), Maleic acid crosslinking of C-6 fluorocarbon as oil and water repellent finish on cellulosic fabric, J. Chem. Prod, 112, 3525-3530.

Schindler WD and Hauser PJ, (2004), Chemical finishing of textiles, Cambridge: Woodhead Publishing Ltd, p. 80-82.

Sahin B, (1996), Fluorochemicals in textile finishing, Int. Text. Bull.-Dyeing/Printing/Finishing, 42(3), 26-30

Corpat J M, Dessaint A, (1997), Fluorine-based Textile Finishes, Melliand Textilber. Eng, 78(9), E135-E137

Grottenmuller R, (1998), Fluorocarbons-An Innovative Aid to the Finishing of Textiles,Melliand Int., 4, 278-281

Hangjin Q, Kunyan S, Zhaoli M, Dong W, Xiquan S, Jianjun Lu, (2002), Polymeric Fluorocarbon Coated Polyester Substrates for Waterproof Breathable Fabrics, Textile Res. J.72(2), 93-97 